\title{
Approach bias for erotic stimuli in heterosexual male college students who use pornography
}

\author{
SKYLER SKLENARIK ${ }^{1}$, MARC N. POTENZA ${ }^{2,3,4}$, MATEUSZ GOLA ${ }^{5,6}$, ARIEL KOR ${ }^{7}$, SHANE W. KRAUS ${ }^{8,9}$ and \\ ROBERT S. ASTUR ${ }^{1 *}$ \\ ${ }^{1}$ Department of Psychological Sciences, University of Connecticut, Storrs, CT, USA \\ ${ }^{2}$ Departments of Psychiatry and Neuroscience and Child Study Center, Yale University School of Medicine, New Haven, CT, USA \\ ${ }^{3}$ Connecticut Council on Problem Gambling, Wethersfield, CT, USA \\ ${ }^{4}$ Connecticut Mental Health Center, New Haven, CT, USA \\ ${ }^{5}$ Institute for Neural Computations, University of California San Diego, La Jolla, CA, USA \\ ${ }^{6}$ Institute of Psychology, Polish Academy of Sciences, Warsaw, Poland \\ ${ }^{7}$ School of Psychology, Israel Center on Addiction, Herzliya, Israel \\ ${ }^{8}$ VISN 1 New England MIRECC, Edith Nourse Rogers Memorial Veterans Hospital, Bedford, MA, USA \\ ${ }^{9}$ Division of Addiction Psychiatry, University of Massachusetts Medical School, Worcester, MA, USA
}

(Received: November 12, 2018; revised manuscript received: April 18, 2019; second revised manuscript received: May 18, 2019; accepted: May 25, 2019)

\begin{abstract}
Background and aims: Addicted individuals often demonstrate relatively automatic action tendencies in response to addiction-related stimuli, whereby they approach rather than avoid addictive stimuli. This study assessed whether an approach bias for erotic stimuli exists among heterosexual college-aged males who report using pornography. Methods: We tested 72 male undergraduate students using an approach-avoidance task employing erotic stimuli, during which participants were instructed to push or pull a joystick in response to image orientation. To simulate approach and avoidance movements, pulling the joystick enlarged the image and pushing shrunk the image. Frequency and severity of pornography use was assessed using a Brief Pornography Screener and the Problematic Pornography Use Scale (PPUS). Results: Participants demonstrated a significant approach bias for erotic stimuli as compared to neutral stimuli, and this approach bias significantly correlated with pornography-use measures. Moreover, individuals with problematic pornography use (as classified by the PPUS) showed more than double the approach bias than did nonproblematic users. Discussion and conclusion: The observation of cognitive biases for erotic stimuli in individuals with problematic pornography use indicate similarities between behavioral and substance addictions.
\end{abstract}

Keywords: addiction, pornography, approach bias, avoidance, cognitive bias

\section{INTRODUCTION}

Studies of the cognitive processes underlying responses to appetitive stimuli (e.g., images of alcohol or drugs as related to substance-use disorders) have provided important insight into addictive disorders, identifying implicit responses and biases that likely contribute to the development and maintenance of addictive behaviors (Field \& Cox, 2008). Associations between subconscious cognitive biases and addictive behaviors have been found using cross-sectional and prospective experimental designs employing a variety of methods, including joystick tasks (Cousijn, Goudriaan, \& Wiers, 2011; Krieglmeyer \& Deutsch, 2010; Wiers, Eberl, Rinck, Becker, \& Lindenmeyer, 2011), stimulus-response compatibility (SRC) tasks (Field, Kiernan, Eastwood, \& Child, 2008; Krieglmeyer \& Deutsch, 2010), and visual-probe tasks (Mechelmans et al., 2014; Pekal, Laier, Snagowski, Stark, \& Brand, 2018; Schoenmakers, Wiers, Jones, Bruce, \& Jansen, 2007). Correlations between cognitive biases, which may reflect motivational tendencies in part generated from learned associations, and addictive behaviors have been observed in both clinical and nonclinical populations in age groups ranging from older children and adolescents to adults (Stacy \& Wiers, 2010).

A key cognitive process involved in addictive behaviors is approach bias, or the relatively automatic action tendency to move certain stimuli toward the body (or to move the body toward certain stimuli) rather than away from it (Field et al., 2008). According to dual processing models of addiction, addictive behaviors develop as a result of an imbalance between an appetitive, "impulsive" motivational system and a regulatory executive system (Cousijn et al., 2011; Stacy \& Wiers, 2010; Wiers et al., 2007; Wiers, Rinck, Dictus, \& van den Wildenberg, 2009). The appetitive system mediates physiological processes involved in

* Corresponding author: Robert S. Astur; Department of Psychological Sciences, University of Connecticut, 406 Babbidge Road, Unit 1020, Storrs, CT 06269-1020, USA; Phone: +1 203236 9938; Fax: +1 203236 9800; E-mail: robert.astur@uconn.edu

This is an open-access article distributed under the terms of the Creative Commons Attribution-NonCommercial 4.0 International License, which permits unrestricted use, distribution, and reproduction in any medium for non-commercial purposes, provided the original author and source are credited, a link to the CC License is provided, and changes - if any - are indicated. 
attention and action, which may lead individuals to evaluate stimuli based on motivation significance and trigger the development of automatic action tendencies to approach addictive stimuli (Bradley, Codispoti, Cuthbert, \& Lang, 2001; Wiers et al., 2009). Repeated and prolonged engagement in addictive behaviors may strengthen appetitive responses, simultaneously increasing automatic responses and weakening executive control to regulate impulses; in sum, addiction-related behaviors may become quick, effortless, difficult to control, and regulated mostly outside of awareness (Stacy \& Wiers, 2010; Tiffany \& Conklin, 2000; Wiers et al., 2007).

Indeed, approach biases have been implicated in multiple addictive behaviors using different experimental approaches. For instance, Field et al. (2008) used a SRC task - from which the approach-avoidance task (AAT) is derived - to demonstrate that heavy drinkers (but not light drinkers) are faster to move a manikin toward, rather than away from, alcohol stimuli. The SRC tasks have also identified approach biases in tobacco smokers (Bradley, Field, Mogg, \& De Houwer, 2004) and regular cannabis users (Field, Eastwood, Mogg, \& Bradley, 2006). Similarly, Wiers et al. (2011) found that during an alcohol-AAT, heavy drinkers were faster to approach than avoid alcohol pictures, but not nonalcohol-related stimuli. On the whole, these studies suggest that addicted individuals tend to respond to drug-related cues with approach responses, and that such cues may therefore elicit approach tendencies in frequent users (Field et al., 2008).

Furthermore, approach biases likely interact with other cognitive biases, such as attentional biases and evaluative biases, to create an addiction-oriented motivational system that maintains addictive behaviors. Literature suggests that in addition to displaying automatic approach tendencies for addiction-related cues, addicted individuals are also likely to attend to them preferentially (i.e., spend more time looking at them) and to evaluate them as more positive and arousing than other available cues in the environment (Cousijn et al., 2011; Field \& Cox, 2008; Stacy \& Wiers, 2010). The interrelation of these biases is elucidated by the incentive sensitization theory, which posits that a hypersensitivity to the motivational effects of addiction-related cues produces an attentional bias for these cues, problematic motivation to engage in the addictive behavior, and the activation of approach behaviors (Stacy \& Wiers, 2010). Critically, preferential attentional processing for addictionrelated cues has been repeatedly associated with quantity and frequency of substance use and severity of substanceuse disorders, in addition to the potential risk of relapse after abstinence; this effect has been found with respect to use of alcohol, tobacco, cannabis, opiates, and cocaine (Field \& Cox, 2008; Schoenmakers et al., 2007). Thus, cognitive biases, problematic motivation, and engagement in addictive behaviors appear interconnected.

Data suggest that behavioral or non-substance addictions (e.g., gambling disorder) share underlying features and mechanisms with substance addictions (Grant, Brewer, \& Potenza, 2007; Grant, Potenza, Weinstein, \& Gorelick, 2010). Behavioral addictions resemble substance addictions in phenomenology (e.g., tolerance and withdrawal), natural history, comorbidity with psychiatric disorders, genetic contributions, neurobiological correlates, adverse consequences (such as psychological distress and impairments in various domains of functioning), and responses to treatment (Grant et al., 2010; Petry, 2015; Potenza, 2006). Behavioral addictions also share other clinical features with substance-use disorders, including diminished behavioral control, appetitive craving, and difficulties cutting back or stopping engagement in the addictive behavior despite adverse consequences (Grant et al., 2007, 2010).

Accordingly, cognitive biases have been implicated in both behavioral and substance addictions (Potenza, 2014). For example, individuals with pathological gambling have performed more poorly on measures of higher-order attention and executive functioning in some but not all studies, with more consistent findings linking gambling and substance-use disorders on tasks involving ventromedial prefrontal cortical contributions (Grant et al., 2007; Lawrence, Luty, Bogdan, Sahakian, \& Clark, 2009; Potenza, 2014, 2017). As ventromedial prefrontal cortical processes have been implicated in processing rewarding outcomes and decision-making (Leeman \& Potenza, 2012; Potenza, 2017), cognitive biases similar to those involved in substance addictions may be implicated in other behavioral addictions.

To date, the main nomenclature systems describing psychiatric disorders [i.e., the fifth edition of the Diagnostic and Statistical Manual of Mental Disorders and 11th edition of the International Classification of Diseases (ICD-11)] only specify non-substance addictions related to gambling and gaming (Petry, 2015; Potenza, 2018). Problematic use of pornography and other compulsive sexual behaviors have been proposed for consideration as behavioral addictions and share neurobiological and neurocognitive features with substance addictions (Gola \& Draps, 2018; Kowalewska et al., 2018; Stark, Klucken, Potenza, Brand, \& Strahler, 2018), although compulsive sexual behavior disorder has been proposed as an impulse-control disorder in ICD-11 (Kraus et al., 2018). At present, more research is needed to examine the extent to which frequent or problematic pornography use may exhibit clinically relevant similarities with or differences from other addictive behaviors. The use of experimental designs may help illuminate clinical features or behavioral tendencies associated with frequent pornography use.

Therefore, the purpose of this study was to determine whether an approach bias for erotic stimuli exists among college-aged males who use pornography and the extent to such a bias may relate to problematic pornography use. Pornography consumption is a prevalent behavior among college-aged individuals. Giordano and Cashwell (2017) report that $43.1 \%$ of college students view pornography at least once a week; over $10 \%$ of these students meet the criteria for cybersex addiction. Pornography use is more prevalent in younger versus older populations and in men more than women (Brown, Durtschi, Carroll, \& Willoughby, 2017). Negative outcomes related to problematic pornography use include risky sexual behaviors (e.g., condomless sex), poor relationship outcomes, depression, and reduced sexual and life satisfaction (Braithwaite, Coulson, Keddington, \& Fincham, 2015; Schiebener, Laier, \& Brand, 2015; Wright, Tokunaga, \& Kraus, 2016). Considering the accessibility, availability, and affordability of pornography 
(Cooper, Delmonico, \& Burg, 2000) and the fact that neither motivational processes nor executive functioning may be fully developed in adolescents or young adults (Chambers, Taylor, \& Potenza, 2003), the college population may be at elevated risk of problematic pornography use.

It seems likely that analogous cognitive mechanisms operate in problematic pornography use and substance addictions. Indeed, several studies suggest that individuals who engage in compulsive sexual behaviors show both attentional biases (Mechelmans et al., 2014) and approach-avoidance tendencies for erotic stimuli; however, findings on the latter are mixed. For example, Snagowski and Brand (2015) modified an AAT with pornographic pictures and observed that individuals who self-reported more symptoms of cybersex addiction tended to either approach or avoid pornographic stimuli, but not neutral stimuli. These findings indicate a curvilinear rather than linear relationship between symptoms of problematic pornography use and approach-avoidance tendencies, such that greater symptomology is associated with more approach or avoidance tendencies, and moderate symptomology is not (Snagowski \& Brand, 2015). In contrast, Stark et al. (2017) found only a positive linear relationship between problematic Internet pornography use and approach-avoidance scores on an AAT modified with sexually explicit material. Moreover, in a neuroimaging study, individuals with problematic pornography use reacted faster to cues predicting erotic pictures than to those predicting monetary gains, and this rapid-response tendency was related to stronger recruitment of the ventral striatum and severity of clinical symptoms of sexual addiction and hypersexuality (Gola et al., 2017). Tendencies toward cybersex addiction have also been associated with difficulties exerting cognitive control over a multitasking situation involving neutral and pornographic pictures (Schiebener et al., 2015). These data suggest that impaired control may be related to problematic pornography use as in substance and behavioral addictions. Taken together, it seems plausible that cognitive biases for erotic stimuli may be found in relation to problematic pornography use, the severity of use, and subjective craving (Mechelmans et al., 2014; Snagowski \& Brand, 2015; Stark et al., 2017).

This study aimed to measure approach and avoidance tendencies among male college students who consume pornography using an AAT modified with erotic stimuli; the zooming feature coupled with arm extension and flexion on the joystick AAT may simulate realistic approach and avoidance tendencies (Cousijn et al., 2011; Wiers et al., 2009). In the context of prior findings, we hypothesized that male college students who reported using pornography would display an approach bias for erotic versus neutral stimuli and that measures of problematic pornography use would be related to the degree of approach.

\section{METHODS}

\section{Participants}

Seventy-two male undergraduate students from the University of Connecticut (average age $=19.5$ years, $S D=2.4$ ) who self-identified as users of pornography were recruited from the Psychology Department's online participant pool. Sexual preference was assessed using a question from the Kinsey scale (Kinsey, Pomeroy, \& Martin, 1948/1988). Participants received class credit for their participation. The study was approved by the Institutional Review Board at the University of Connecticut.

\section{Materials}

Participants were seated in front of a computer and asked to complete questionnaires prior to performing a computerized AAT. Questionnaires assessed frequency and severity of pornography use as well as attitudes toward pornography. Scales included the Problematic Pornography Use Scale (PPUS) and the Brief Pornography Screener (BPS), both of which quantify pornography use and related attitudes. The PPUS (Kor et al., 2014) is a 12-item scale that asks individuals to assess statements about their pornography use over the past year on a 6-point Likert scale ranging from "never true" to "almost always true." The scale includes statements such as, "I was unsuccessful in my efforts to reduce or to control the frequency of my use of pornography" and "I spend too much time thinking about pornography" (Kor et al., 2014). Similarly, the BPS asks individuals to respond to five situations in regard to their use of pornography over the past 6 months on a 3-point Likert scale from "never" to "very often," and consists of items such as, "You continue to use sexually explicit material even though you feel guilty about it" (Kraus et al., 2017). The BPS is a screening scale that measures only one aspect of problematic pornography use - control or lack thereof over behavior - and may be useful in identifying individuals at risk of problematic pornography use or as a proxy measure. In comparison, the PPUS is a multidimensional scale that assesses four aspects of problematic pornography use and may therefore provide a broader picture of problematic pornography use symptomology (Kor et al., 2014).

We used a modified version of the AAT utilized by Wiers et al. (2011), in which participants are instructed to push or pull a joystick in response to pictures based on irrelevant properties of the picture content (e.g., whether the picture is oriented horizontally or vertically). Each computer was equipped with a standard gaming joystick and headphones and all of the software was custom-written by the author RSA. Prior studies have indicated that the approach-avoidance joystick task is a valid method for activating implicit approach-avoidance behaviors based on the valence of pictorial cues (Krieglmeyer \& Deutsch, 2010). Furthermore, Wiers et al. (2009) suggest that when a reliable difference in approach and avoidance movements is found in response to irrelevant picture features (as compared to relevant features), the responses are more likely to be automatic and thus regulated outside of conscious awareness.

The AAT task in this study consisted of 50 erotic pictures of females, heterosexual couples, and female couples and 50 neutral pictures of common household items, such as a lamp or a clock. Erotic stimuli were selected in line with multiple studies reporting that erotica depicting females or couples (male/female and female/female) are subjectively rated as highly arousing and evoke a strong appetitive 
motivational state, evidenced by physiological response (Bernat, Patrick, Benning, \& Tellegen, 2006; Bradley et al., 2001). Half of the images were $600 \times 800$ pixels and presented vertically (portrait view), and the other half were $800 \times 600$ pixels and presented horizontally (landscape view).

\section{Procedure}

After providing written informed consent, participants were asked to complete the questionnaires administered through Qualtrics, an online survey service. Following this, the participants were instructed on how to complete the AAT. Participants were seated in front of a computer and were instructed to pull the joystick in response to the images oriented vertically (portrait $-600 \times 800$ pixels) and to push the joystick in response to the images oriented horizontally (landscape $-800 \times 600$ pixels). Pulling the joystick made the picture increase in size, generating a sensation of approach; pushing the joystick made the picture decrease in size, simulating an avoidance movement. The initial actual image size was 3 in. $\times 4$ in. for the vertical images and 4 in. $\times 3$ in. for the horizontal images. Approaching resulted in the picture enlarging continuously in size until it filled the screen and disappeared over a 1-s interval. Avoiding resulted in the picture to shrink continuously until it disappeared over a 1-s interval. Half of both types of stimuli were presented as landscape images and the other half were presented as portrait images. Participants were asked to respond as quickly and accurately as possible throughout 2 series of 100 test trials. Response time was calculated as the number of milliseconds from when the image was presented on the screen to when the joystick movement was initiated. The first series began with 20 practice trials using colored rectangles, followed by the 50 erotic and 50 neutral stimuli presented in a pseudorandom order. The second series occurred after a 60 -s break and began with 2 practice trials followed by the 100 test trials. Incorrect answers were denoted by a buzzer noise in the headphones. Each block of trials took about 5 min to complete. After completing the AAT, participants were debriefed and dismissed.

\section{Data analysis}

Cognitive bias data were calculated in the same manner as found by Wiers et al. (2011) for the AAT, responses that were incorrect/missed and response times longer than three $S D$ s above the mean were discarded based on each participant's performance. Erotic approach bias scores were calculated by subtracting median reaction times:

$$
\begin{aligned}
{[(\text { erotic push }} & - \text { erotic pull })-(\text { neutral push } \\
& - \text { neutral pull })]
\end{aligned}
$$

Hence, a positive value indicated a cognitive bias for erotic stimuli. One potential criticism of the approach-avoidance joystick task is that it may be sensitive to outliers (Krieglmeyer \& Deutsch, 2010); accordingly, median reaction times were used because they are less sensitive to outliers than means (Rinck \& Becker, 2007; Wiers et al., 2009).

\section{Ethics}

After providing written informed consent, the study was approved by the Institutional Review Board at the University of Connecticut.

\section{RESULTS}

Seventy-two participants completed the experiment. Eight participants were excluded due to indicating a sexual preference that was not a heterosexual preference (i.e., they had a score higher than 1) on the Kinsey scale (Kinsey et al., 1948/1988), and an additional six participants were excluded due to incomplete or extreme data (i.e., greater than three $S D$ s above the mean). This resulted in 58 complete data sets.

A one-sample $t$-test showed that there was a significant approach bias of $81.81 \mathrm{~ms}(S D=93.07)$ for the erotic images, $t(57)=6.69, p<.001$, compared to the neutral images (Figure 1). In addition, on examining correlations between the assessments and approach bias scores, we found a significant correlation between BPS and approach bias scores, $r=.26, p<.05$, indicating that the higher the BPS score, the stronger the approach bias (Figure 2). The correlation between the PPUS and approach bias scores was not significant, $r=.19$, ns. There was a strong correlation between the BPS and PPUS scores, $r=.77, p<.001$.

To examine cognitive bias in those at high risk of problematic pornography use, a total score of 28 or more on the PPUS was used as a threshold for problematic pornography use as suggested by the author AK. Accordingly, four participants in our sample were categorized as problematic pornography users based on this criterion. We conducted a one-way analysis of variance (ANOVA) to determine if cognitive bias scores differed significantly between the two groups. The individuals with problematic pornography use demonstrated a significantly stronger approach bias score [186.57 $\mathrm{ms}(S D=135.96), n=4]$ compared to individuals without problematic pornography use [74.04 ms $(S D=85.91), n=54], F(1,56)=5.91, p<.05$ (Table 1).

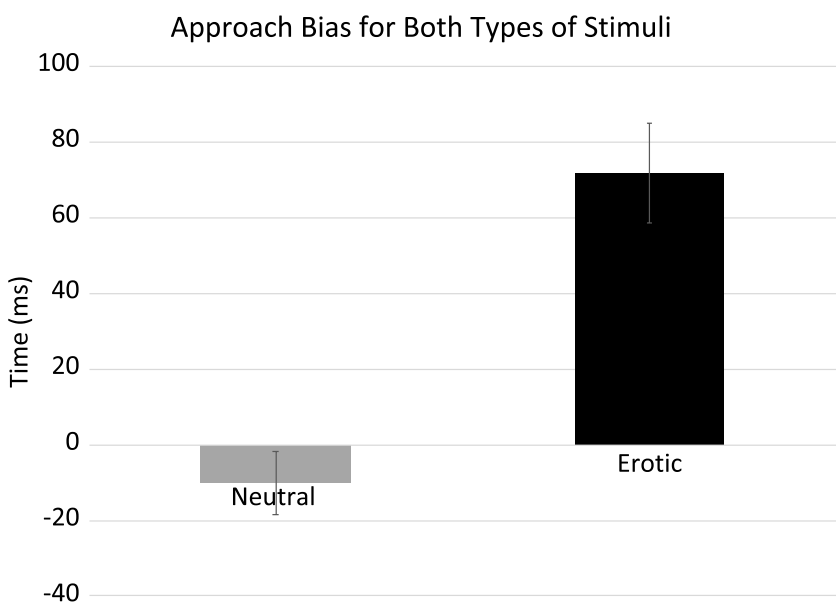

Figure 1. There was no approach bias for the neutral stimuli, but a significant $(p<.001)$ approach bias for the erotic stimuli.

Approach bias scores were calculated by subtracting median reaction times: $\left(R T_{\text {push }}-R T_{\text {pull }}\right)$ 


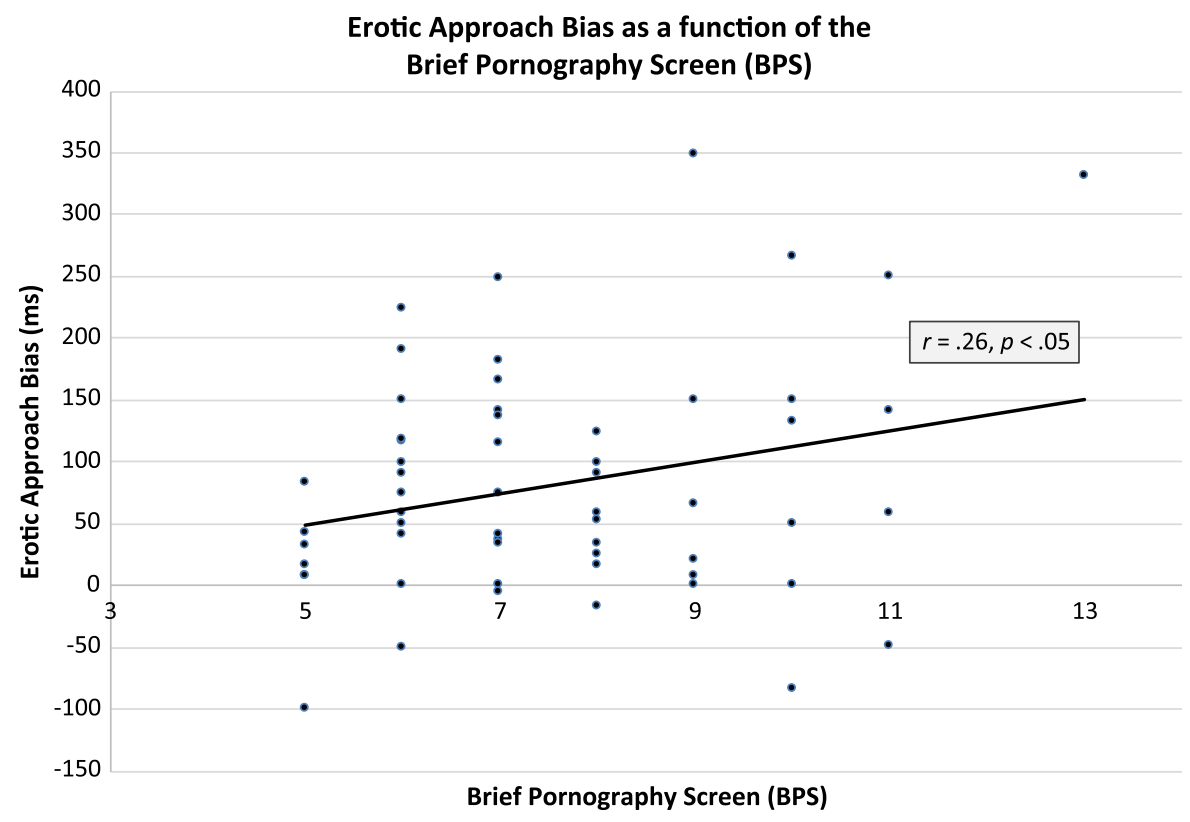

Figure 2. There was a significant positive correlation between scores on the BPS and approach bias $(r=.26, p<.05)$, indicating that the higher the BPS score, the stronger the approach bias

Table 1. Average BPS and PPUS scores and RTs for the four conditions for problematic pornography users in the sample $(N=4)$, defined as individuals that scored 28 or higher on the PPUS

\begin{tabular}{lccccccc}
\hline Age (years) & BPS score & $\begin{array}{c}\text { PPUS } \\
\text { score }\end{array}$ & $\begin{array}{c}\text { Neutral approach } \\
\text { RT }(\mathrm{ms})\end{array}$ & $\begin{array}{c}\text { Neutral avoid } \\
\text { RT }(\mathrm{ms})\end{array}$ & $\begin{array}{c}\text { Erotic approach } \\
\text { RT (ms) }\end{array}$ & $\begin{array}{c}\text { Erotic avoid } \\
\text { RT (ms) }\end{array}$ & $\begin{array}{c}\text { Erotic approach } \\
\text { bias (ms) }\end{array}$ \\
\hline $19.5(1.3)$ & $10.25(2.2)$ & $29.75(0.9)$ & $968(263.3)$ & $985(304)$ & $1,106(366.7)$ & $1,310(494.9)$ & $187(136)^{*}$ \\
\hline
\end{tabular}

Note. BPS: Brief Pornography Screener; PPUS: Problematic Pornography Use Scale; RT: reaction time.

$* p<.05$.

Because of the difference in group sizes, there is some concern about homogeneity of variance between the groups. Accordingly, we ran a Levene's test of homogeneity of variances and found that there was no significant difference between the groups, hence suggesting that the ANOVA is applicable in this case (Levene's statistic $=1.79$, $\left.d f_{1}=1, d f_{2}=56, p=.19\right)$.

\section{DISCUSSION}

The results support the hypothesis that heterosexual male college students who use pornography are faster to approach than to avoid erotic stimuli during an AAT task. There was a significant approach bias of $81.81 \mathrm{~ms}$ for erotic stimuli; that is, participants were faster to move toward erotic images compared to moving away from erotic images. Participants were faster to pull the joystick than to push it in response to erotic stimuli, but this same bias was not present with regard to neutral stimuli. Similar approach biases have been reported in studies using modified AATs, such as that of Stark et al. (2017) using an erotic-AAT and Wiers et al. (2011) using an alcohol-AAT. These findings are also in line with several SRC tasks suggesting that addicted individuals display an action tendency to approach rather than avoid addictive stimuli (Bradley et al., 2004; Field et al., 2006, 2008).

Overall, the findings suggest that approach for addictive stimuli may be a more rapid or prepared response than avoidance, which may be explained by the interplay of other cognitive biases in addictive behaviors. As suggested by the literature (Cousijn et al., 2011; Field \& Cox, 2008; Stacy \& Wiers, 2010), individuals who display automatic approach tendencies for addiction-related cues also tend to look at them longer (indeed, on average, participants looked at erotic images over $100 \mathrm{~ms}$ longer than neutral images before pushing them away; Table 2) and to evaluate them as more positive and arousing than other cues, such as neutral stimuli. Accordingly, findings reported by Mechelmans et al. (2014) indicate that individuals with compulsive sexual behaviors show attentional biases for erotic stimuli. Future studies should explore roles, both separately and together, of approach, attentional, and evaluative biases in problematic pornography use. It is worth noting that this approach bias for erotic stimuli is not necessarily indicative of addiction risk; it is plausible that pornography users have a general positive attitude toward erotic stimuli or simply prefer it over neutral stimuli. Indeed, erotic stimuli have a greater emotional valence than common household items, such as a lamp or desk. Furthermore, erotic stimuli inherently evoke a strong appetitive emotional state (Bradley et al., 2001), suggesting that individuals may be inclined to approach erotic stimuli regardless of addiction risk.

Moreover, total scores on the BPS were positively correlated with approach bias scores, indicating that the greater the severity of problematic pornography use, the stronger the degree of approach for erotic stimuli. This association 
Table 2. Average BPS and PPUS scores and RTs for the four conditions in the entire sample $(N=58)$

\begin{tabular}{lccccccc}
\hline Age (years) & $\begin{array}{c}\text { BPS } \\
\text { score }\end{array}$ & $\begin{array}{c}\text { PPUS } \\
\text { score }\end{array}$ & $\begin{array}{c}\text { Neutral approach } \\
\text { RT }(\mathrm{ms})\end{array}$ & $\begin{array}{c}\text { Neutral avoid } \\
\text { RT }(\mathrm{ms})\end{array}$ & $\begin{array}{c}\text { Erotic approach } \\
\text { RT (ms) }\end{array}$ & $\begin{array}{c}\text { Erotic avoid } \\
\text { RT (ms) }\end{array}$ & $\begin{array}{c}\text { Erotic approach } \\
\text { bias (ms) }\end{array}$ \\
\hline $19.5(2.4)$ & $7.59(1.9)$ & $17.98(5.5)$ & $865(168.6)$ & $855(157.1)$ & $915(216.6)$ & $987(261.6)$ & $82(93.1)^{*}$ \\
\hline
\end{tabular}

Note. BPS: Brief Pornography Screener; PPUS: Problematic Pornography Use Scale; RT: reaction time.

$* p<.001$.

was further supported by results suggesting that individuals with problematic pornography use, as classified by the PPUS, showed more than a $200 \%$ stronger approach bias for erotic stimuli compared to individuals without problematic pornography use. However, this last finding should be considered particularly cautiously given the small number meeting the criteria for problematic pornography use. These findings resonate with those in studies of addictions indicating that approach bias for addiction-related stimuli is a common feature present in individuals with addictions (Bradley et al., 2004; Cousijn, et al., 2011; Field et al., 2006; Krieglmeyer \& Deutsch, 2010; Wiers et al., 2011). In line with research showing that preferential attentional processing for addiction-related cues is associated with severity of addictive behaviors (Field \& Cox, 2008; Schoenmakers et al., 2007), we found that approach bias scores were positively associated with scores on the BPS, which may be used as a measure reflecting severity of problematic pornography use.

However, our results differ from those denoting a curvilinear relationship between symptoms of cybersex addiction and approach-avoidance tendencies in student and nonstudent samples from Germany (Snagowski \& Brand, 2015). Similar to the findings of Stark et al. (2017), individuals with greater pornography use problems in this study showed only approach biases for erotic stimuli, not avoidance biases. One possible explanation for this contrast is that Snagowski and Brand (2015) used a task-relevant instruction (i.e., move the joystick according to picture content), whereas this study and that of a study by Stark et al. (2017) used task-irrelevant instructions (i.e., move according to picture orientation or color of the picture frames). The taskrelevant instructions may compel participants to process the stimuli more deeply, which may lead to avoidance behavior among users that feel guilt or fear negative consequences related to their behaviors (Stark et al., 2017). While taskirrelevant instructions may not warrant the same level of processing, Wiers et al. (2009) reported that approach movements found in response to irrelevant picture features were more likely to be automatic and unconscious. In sum, given apparent differences across studies performed in different jurisdictions, different samples (student vs. student/non-student), and precise methodologies, further research is needed to understand approach and avoidance behaviors in different populations, using different versions of the AAT. Nonetheless, 4 of 58 subjects (6.89\%) met a threshold of 28 points using the PPUS, and this finding is in line with previous studies reporting approximately $10 \%$ of cybersex addiction prevalence among male college students (Giordano \& Cashwell, 2017).

Taken together, the results suggest parallels between substance and behavioral addictions (Grant et al., 2010).
Pornography use (particularly problematic use) was linked to faster approaches to erotic stimuli than neutral stimuli, an approach bias similar to that observed in alcohol-use disorders (Field et al., 2008; Wiers et al., 2011), cannabis use (Cousijn et al., 2011; Field et al., 2006), and tobacco-use disorders (Bradley et al., 2004). An overlap between cognitive features and neurobiological mechanisms involved in both substance addictions and problematic pornography use seems likely, which is consistent with prior studies (Kowalewska et al., 2018; Stark et al., 2018). Nonetheless, additional studies are warranted of cognitive biases, especially in other pornography-using groups (in both clinical and non-clinical populations including women, non-heterosexual individuals, and multiple age groups outside of college-aged), as are studies of the neurobiological and clinical correlates.

\section{Limitations and future directions}

Limitations should be noted. First, this study examined data from only heterosexual male participants who viewed pornography. Future studies should examine potential cognitive biases in males of other sexual orientations (e.g., homosexual and bisexual), females of varying sexual orientations, as well as transgender and other groups (e.g., kink and polyamorous). Other factors that may potentially influence cognitive biases (such as onset of regular pornography use or amount of pornography use during the average week and preceding the study) were not collected and should be examined in future studies. Additional studies should also examine for possible cognitive biases that may exist independent of pornography viewing (e.g., in a group of individuals who do not view pornography).

In addition, asking questions regarding pornography use may have influenced responding during the task. However, associations between scores on scales screening or assessing for problematic pornography suggest a relationship between approach biases and extent of pornography use problems, mitigating against these concerns and suggesting that cognitive biases should be examined further in future studies. As such, our analysis of approach biases in problematic pornography use requires a larger sample of individuals with problematic pornography use. A study examining approach biases in problematic pornography use may better illuminate the roles of cognitive biases in its course (e.g., during treatment and recovery). Additional studies could also investigate treatments based on cognitive biases, given the data supporting their efficacy in substance addictions (Gu et al., 2015; Wiers et al., 2011). For example, inpatients with alcohol-use problems were implicitly or explicitly trained to avoid alcohol stimuli rather than approach it using a joystick paradigm. This manipulation of the action tendency to approach alcohol resulted in a new avoidance 
bias for alcohol and decreased alcohol consumption; moreover, better treatment outcome was observed 1 year later (Wiers et al., 2011). Potentially, cognitive retraining programs could have significant clinical implications for treating problematic pornography use, and this possibility should be tested directly in future studies.

Funding sources: This project was partially supported by funding to SS by the Connecticut Institute for the Brain and Cognitive Sciences at the University of Connecticut. Dr. MNP received support to Yale or the Connecticut Mental Health Center from the National Center for Responsible Gaming, the Connecticut Council on Problem Gambling, and the Connecticut Department of Mental Health and Addiction Services.

Authors' contribution: RSA and Dr. MNP planned the study design. RSA programmed the task. MG discussed and provided imagery relevant to the erotic stimuli. SWK and AK developed and provided information about the pornography assessments employed in the study. SS obtained support and conducted data collection. SS in conjunction with RSA generated the initial draft of the manuscript. All authors provided input, read, and reviewed the manuscript prior to submission.

Conflict of interest: The authors have no conflicts of interest with respect to the content of this manuscript. Dr. MNP has received financial support or compensation for the following: he has consulted for and advised RiverMend Health, Opiant/Lakelight Therapeutics, and Jazz Pharmaceuticals; has received unrestricted research support from Mohegan Sun Casino and grant support (to Yale) from the National Center for Responsible Gaming and Pfizer pharmaceuticals; has participated in surveys, mailings, or telephone consultations related to drug addiction, impulse-control disorders, or other health topics; has consulted for legal and gambling entities on issues related to impulse-control disorders and addictions including with respect to dopaminergic drugs; has provided clinical care in the Connecticut Department of Mental Health and Addiction Services Problem Gambling Services Program; has performed grant reviews for the National Institutes of Health and other agencies; has edited journals and journal sections; has given academic lectures in grand rounds, CME events and other clinical or scientific venues; and has generated books or book chapters for publishers of mental health texts.

\section{REFERENCES}

Bernat, E., Patrick, C. J., Benning, S. D., \& Tellegen, A. (2006). Effects of picture content and intensity on affective physiological response. Psychophysiology, 43(1), 93-103. doi:10.1111/ j.1469-8986.2006.00380.x

Bradley, B. P., Field, M., Mogg, K., \& De Houwer, J. (2004). Attentional and evaluative biases for smoking cues in nicotine dependence: Component processes of biases in visual orienting. Behavioural Pharmacology, 15(1), 29-36. doi:10.1097/00008877-200402000-00004

Bradley, M. M., Codispoti, M., Cuthbert, B. N., \& Lang, P. J. (2001). Emotional and motivation I: Defensive and appetitive reactions in picture processing. Emotion, 1(3), 276-298. doi:10.1037/1528-3542.1.3.276

Braithwaite, S. R., Coulson, G., Keddington, K., \& Fincham, F. D. (2015). The influence of pornography on sexual scripts and hooking up among emerging adults in college. Archives of Sexual Behavior, 44(1), 111-123. doi:10.1007/s10508-014-0351-x

Brown, C. C., Durtschi, J. A., Carroll, J. S., \& Willoughby, B. J. (2017). Understanding and predicting classes of college students who use pornography. Computers in Human Behavior, 66, 114-121. doi:10.1016/j.chb.2016.09.008

Chambers, R. A., Taylor, J. R., \& Potenza, M. N. (2003). Developmental neurocircuitry of motivation in adolescence: A critical period of addiction vulnerability. American Journal of Psychiatry, 160(6), 1041-1052. doi:10.1176/appi.ajp.160.6.1041

Cooper, A., Delmonico, D. L., \& Burg, R. (2000). Cybersex users, abusers, and compulsives: New findings and implications. Sexual Addiction \& Compulsivity, 7(1-2), 5-29. doi:10.1080/ 10720160008400205

Cousijn, J., Goudriaan, A. E., \& Wiers, R. W. (2011). Reaching out towards cannabis: Approach-bias in heavy cannabis users predicts changes in cannabis use. Addiction, 106(9), 1667-1674. doi:10.1111/j.1360-0443.2011.03475.x

Field, M., \& Cox, W. M. (2008). Attentional bias in addictive behaviors: A review of its development, causes, and consequences. Drug and Alcohol Dependence, 97(1-2), 1-20. doi:10.1016/j.drugalcdep.2008.03.030

Field, M., Eastwood, B., Mogg, K., \& Bradley, B. P. (2006). Selective processing of cannabis cues in regular cannabis users. Drug and Alcohol Dependence, 85(1), 75-82. doi:10.1016/j. drugalcdep.2006.03.018

Field, M., Kiernan, A., Eastwood, B., \& Child, R. (2008). Rapid approach responses to alcohol cues in heavy drinkers. Journal of Behavior Therapy and Experimental Psychiatry, 39(3), 209-218. doi:10.1016/j.jbtep.2007.06.001

Giordano, A. L., \& Cashwell, C. S. (2017). Cybersex addiction among college students: A prevalence study. Sexual Addiction \& Compulsivity, 24(1-2), 47-57. doi:10.1080/10720162. 2017.1287612

Gola, M., \& Draps, M. (2018). Ventral striatal reactivity in compulsive sexual behaviors. Frontiers in Psychiatry, 9, 1-9. doi:10.3389/fpsyt.2018.00546

Gola, M., Wordecha, M., Sescousse, G., Lew-Starowicz, M., Kossowski, B., Wypych, M., Potenza, M. N., \& Marchewka, A. (2017). Can pornography be addictive? An fMRI study of men seeking treatment for problematic pornography use. Neuropsychopharmacology, 42(10), 2021-2031. doi:10.1038/ npp. 2017.78

Grant, J. E., Brewer, J. A., \& Potenza, M. N. (2007). The neurobiology of substance and behavioral addictions. CNS Spectrums, 11(12), 924-930. doi:10.1017/S109285290001511X

Grant, J. E., Potenza, M. N., Weinstein, A. M., \& Gorelick, D. A. (2010). Introduction to behavioral addictions. The American Journal of Drug and Alcohol Abuse, 36(5), 233-241. doi:10.3109/00952990.2010.491884

Gu, X., Lohrenz, T., Salas, R., Baldwin, P. R., Soltani, A., Kirk, U., Cinciripini, P. M., \& Montague, P. R. (2015). Belief about nicotine selectively modulates value and reward prediction 
error signals in smokers. Proceedings of the National Academy of Sciences of the United States of America, 112(8), 2539-2544. doi:10.1073/pnas.1416639112

Kinsey, A., Pomeroy, W. B., \& Martin, C. E. (1948/1988). Sexual behavior in the human male. Philadelphia, PA/Bloomington, IN: W.B. Saunders/Indiana University Press.

Kor, A., Zilcha-Mano, S., Fogel, Y., Mikulincer, M., Reid, R., \& Potenza, M. (2014). Psychometric development of the Problematic Pornography Use Scale. Addictive Behaviors, 39(5), 861-868. doi:10.1016/j.addbeh.2014.01.027

Kowalewska, E., Grubbs, J. B., Potenza, M. N., Gola, M., Draps, M., \& Kraus, S. W. (2018). Neurocognitive mechanisms in compulsive sexual behavior disorder. Current Sex Health Reports, 10(4), 255-264. doi:10.1007/s11930-018-0176-z

Kraus, S. W., Gola, M., Kowalewska, E., Lew-Starowicz, M., Hoff, R. A., Porter, E., \& Potenza, M. N. (2017). Brief Pornography Screener: A comparison of US and Polish pornography users. Journal of Behavioral Addictions, 6(S1), 27-28.

Kraus, S. W., Krueger, R. B., Briken, P., First, M. B., Stein, D. J., Kaplan, M. S., Voon, V., Abdo, C. H., Grant, J. E., Atalla, E., \& Reed, G. M. (2018). Compulsive sexual behaviour disorder in the ICD-11. World Psychiatry, 17(1), 109-110. doi:10.1002/ wps. 20499

Krieglmeyer, R., \& Deutsch, R. (2010). Comparing measures of approach-avoidance behavior: The manikin task vs. two versions of the joystick task. Cognition and Emotion, 24(5), 810-828. doi:10.1080/02699930903047298

Lawrence, A. J., Luty, J., Bogdan, N. A., Sahakian, B. J., \& Clark, L. (2009). Problem gamblers share deficits in impulsive decision-making with alcohol-dependent individuals. Addiction (Abingdon, England), 104(6), 1006-10155. doi:10.1111/ j.1360-0443.2009.02533.x

Leeman, R. F., \& Potenza, M. N. (2012). Similarities and differences between pathological gambling and substance use disorders: A focus on impulsivity and compulsivity. Psychopharmacology, 219(2), 469-490. doi:10.1007/s00213011-2550-7

Mechelmans, D. J., Irvine, M., Blanca, P., Porter, L., Mitchell, S., Mole, T. B., Lapa, T. R., Harrison, N. A., Potenza, M. N., \& Voon, V. (2014). Enhanced attentional bias towards sexually explicit cues in individuals with and without compulsive sexual behaviours. PLoS One, 9(8), e105476. doi:10.1371/ journal.pone.0105476

Pekal, J., Laier, C., Snagowski, J., Stark, R., \& Brand, M. (2018). Tendencies toward Internet-pornography-use disorder: Differences in men and women regarding attentional biases to pornographic stimuli. Journal of Behavioral Addictions, 7(3), 574-583. doi:10.1556/2006.7.2018.70

Petry, N. (2015). Behavioral addictions: DSM- $5^{\circledR}$ and beyond. New York, NY: Oxford University.

Potenza, M. N. (2006). Should addictive disorders include nonsubstance-related conditions? Addiction, 101(S1), 142-151. doi:10.1111/j.1360-0443.2006.01591.x

Potenza, M. N. (2014). The neural bases of cognitive processes in gambling disorder. Trends in Cognitive Sciences, 18(8), 429-438. doi:10.1016/j.tics.2014.03.007

Potenza, M. N. (2017). Clinical neuropsychiatric considerations regarding non-substance or behavioral addictions. Dialogues in Clinical Neuroscience, 19(3), 281-291.

Potenza, M. N. (2018). Do gaming disorder and hazardous gaming belong in ICD-11? Considerations regarding the death of a hospitalized patient that was reported to have occurred while a care provider was gaming. Journal of Behavioral Addictions, 7(2), 206-207. doi:10.1556/2006.7.2018.42

Rinck, M., \& Becker, E. S. (2007). Approach and avoidance in fear of spiders. Journal of Behavior Therapy and Experimental Psychiatry, 38(2), 105-120. doi:10.1016/j.jbtep. 2006.10.001

Schiebener, J., Laier, C., \& Brand, M. (2015). Getting stuck with pornography? Overuse or neglect of cybersex cues in a multitasking situation is related to symptoms of cybersex addiction. Journal of Behavioral Addictions, 4(1), 14-21. doi:10.1556/ JBA.4.2015.1.5

Schoenmakers, T., Wiers, R. W., Jones, B. T., Bruce, G., \& Jansen, A. T. M. (2007). Attentional re-training decreases attentional bias in heavy drinkers without generalization. Addiction, 102(3), 399-405. doi:10.1111/j.1360-0443.2006.01718.x

Snagowski, J., \& Brand, M. (2015). Symptoms of cybersex addiction can be linked to both approaching and avoiding pornographic stimuli: Results from an analog sample of regular cybersex users. Frontiers in Psychology, 6(653), 1-14. doi:10.3389/fpsyg.2015.00653

Stacy, A. W., \& Wiers, R. W. (2010). Implicit cognition and addiction: A tool for explaining paradoxical behavior. Annual Review of Clinical Psychology, 6(1), 551-575. doi:10.1146/ annurev.clinpsy.121208.131444

Stark, R., Klucken, T., Potenza, M. N., Brand, M., \& Strahler, J. (2018). A current understanding of the behavioral neuroscience of compulsive sexual behavior disorder and problematic pornography use. Current Behavioral Neuroscience Reports, 5(4), 218-231. doi:10.1007/s40473-018-0162-9

Stark, R., Kruse, O., Snagowski, J., Brand, M., Walter, B., Klucken, T., \& Wehrum-Osinsky, S. (2017). Predictors for (problematic) use of Internet sexually explicit material: Role of trait sexual motivation and implicit approach tendencies towards sexually explicit material. Sexual Addiction \& Compulsivity, 24(3), 180-202. doi:10.1080/10720162.2017. 1329042

Tiffany, S. T., \& Conklin, C. A. (2000). A cognitive processing model of alcohol craving and compulsive alcohol use. Addiction, 95(8 Suppl. 2), 145-153. doi:10.1046/j.1360-0443. 95.8s2.3.x

Wiers, R. W., Bartholow, B. D., van den Wildenberg, E., Thush, C., Engels, R. C. M. E., Sher, K. J., Grenard, J., Ames, S. L., \& Stacy, A. W. (2007). Automatic and controlled processes and the development of addictive behaviors in adolescents: A review and a model. Pharmacology Biochemistry and Behavior, 86(2), 263-283. doi:10.1016/j.pbb.2006.09.021

Wiers, R. W., Eberl, C., Rinck, M., Becker, E. S., \& Lindenmeyer, J. (2011). Retraining automatic action tendencies changes alcoholic patients' approach bias for alcohol and improves treatment outcome. Psychological Science, 22(4), 490-497. doi:10.1177/0956797611400615

Wiers, R. W., Rinck, M., Dictus, M., \& van den Wildenberg, E. (2009). Relatively strong automatic appetitive actiontendencies in male carriers of the OPRM1 G-allele. Genes, Brain and Behavior, 8(1), 101-106. doi:10.1111/j.1601-183X. 2008.00454.x

Wright, P. J., Tokunaga, R. S., \& Kraus, A. (2016). Consumption of pornography, perceived peer norms, and condomless sex. Health Communication, 31(8), 954-963. doi:10.1080/104102 36.2015 .1022936 